\title{
Antimicrobial treatment decision for non-purulent skin and soft tissue infections in the emergency department
}

\author{
Krishan Yadav, MD, MSc*; Mathieu Gatien, MD*; Vicente Corrales-Medina, MD, MSc ${ }^{\dagger \neq}$; \\ Ian Stiell, MD, MSc ${ }^{*}$
}

\section{ABSTRACT}

Objectives: We surveyed Canadian emergency physicians to determine how skin and soft tissue infections (SSTIs) are managed and which risk factors were felt to be important in predicting failure with oral antibiotics.

Methods: We performed an electronic survey of physician members of the Canadian Association of Emergency Physicians (CAEP) using the modified Dillman method.

Results: The survey response rate was $36.9 \%(n=391)$ amongst CAEP members. There was a lack of consensus regarding management of SSTIs. CAEP respondents identified 14 risk factors for predicting treatment failure with oral antibiotics, including hypotension, tachypnea, and patient reported severity of pain $>8$ of 10 .

Conclusions: The survey demonstrates significant variability regarding physician management of SSTIs, and we have identified several perceived risk factors for treatment failure with oral antibiotics that should be assessed in future studies.

\section{RÉSUMÉ}

Objectifs: Une enquête a été menée parmi les médecins d'urgence au Canada afin de déterminer la prise en charge des infections non purulentes (INP) de la peau et des tissus mous, et de cerner les facteurs de risque jugés importants dans la prévisibilité de l'échec du traitement par les antibiotiques par voie orale.

Méthode: Une enquête en ligne a été menée parmi les médecins membres de l'Association canadienne des médecins d'urgence (ACMU), selon une version modifiée de la méthode de Dillman.

Résultats: Le taux de réponse parmi les membres de I'ACMU a atteint $36,9 \%(n=391)$, et un manque de consensus a été relevé quant à la prise en charge des INP de la peau et des tissus mous. Les répondants ont cerné 14 facteurs de risque de prévisibilité de l'échec du traitement par les antibiotiques par voie orale, notamment l'hypotension, la tachypnée et un degré d'intensité de la douleur déclaré par les patients, supérieur à 8/10.

Conclusions: Les résultats de l'enquête démontrent que la prise en charge médicale des INP de la peau et des tissus mous varie passablement, et plusieurs facteurs de risque jugés importants dans la prévisibilité de l'échec du traitement par les antibiotiques par voie orale devraient faire l'objet d'études futures.

Keywords: cellulitis, skin and soft tissue infections, antibiotics, intravenous, treatment failure

\section{INTRODUCTION}

Non-purulent skin and soft tissue infections (SSTIs), cellulitis or erysipelas, are common emergency department (ED) presentations. ${ }^{1,2}$ Emergency physicians must decide on the type of antibiotic, the duration of therapy, the route to administer it (either oral or intravenous), and the time to reassessment. There are studies that make the case for the use of "simple" oral antibiotics for the treatment of "uncomplicated" SSTIs. ${ }^{3}$ A recent ED study found that even a single dose of broad-spectrum intravenous antibiotics prior to discharge was associated with antibiotic-associated diarrhea and Clostridium difficile infection. ${ }^{4}$ Despite this, practice patterns are highly variable. ${ }^{5,6}$ Treatment decisions have been complicated further by the increasing prevalence of community-acquired methicillin-resistant Staphylococcus aureus (CA-MRSA). ${ }^{7-9}$ There is a lack of consensus on the appropriate route of delivery of antibiotics. Disadvantages to employing the intravenous route may include cost, required repeat

From the *Department of Emergency Medicine and tDepartment of Medicine, University of Ottawa, Ottawa, ON; and the $¥$ Ottawa Hospital Research Institute, Ottawa, ON.

Correspondence to: Krishan Yadav, University of Ottawa, 1053 Carling Avenue, F-Main, Room EM-206, Box 227, Ottawa, ON K1Y 4E9; Email: krishanyad@gmail.com. 
visits to the $\mathrm{ED}$, utilization of home nursing resources to deliver intravenous antibiotics, and patient inconvenience and discomfort.

Current guidelines regarding the optimal route of antibiotic delivery are primarily based on expert opinion. ${ }^{10-12}$ Interestingly, a recent prospective cohort study found that $43 \%$ of patients were overtreated with parenteral therapy (according to the Clinical Resource Efficiency Support Team [CREST] guidelines), with the authors suggesting that many of these cases could have been managed as outpatients with oral antibiotic therapy. ${ }^{13}$ Although studies have been conducted in an effort to identify predictors of admission or prolonged hospital stay, ${ }^{14-16}$ published clinical trials aiming to predict failure with oral antibiotics for SSTIs are currently lacking. In fact, a recent Cochrane systematic review on the management of cellulitis identified 25 randomized trials, but no two trials compared the same antibiotics. ${ }^{17}$ The key clinical question is: what are the risk factors that predict failure with oral antibiotics for SSTIs? In other words, when is it appropriate to select the intravenous route?

To our knowledge, no studies have specifically addressed how physicians decide when a patient is likely to fail oral antibiotic therapy (and thus require intravenous therapy). The objective of this study was to survey Canadian emergency physicians to determine how management of SSTIs is approached. Furthermore, we sought to gauge physician opinion on which factors are considered to be most important in predicting failure with oral antibiotic therapy.

\section{METHODS}

\section{Survey}

\section{Study design and population}

We conducted a self-administered electronic survey of physician members of the Canadian Association of Emergency Physicians (CAEP). In addition, we surveyed physician members of the Association of Medical Microbiology and Infectious Disease Canada (AMMI; see Appendix). Residents and medical students were excluded from the survey population.

\section{Survey content and administration}

Development of the 61-question survey (see Appendix) was overseen by a researcher (IS) with extensive experience in survey design and implementation. ${ }^{18-21}$
For the survey creation, we also sought feedback from several emergency medicine and infectious disease physicians from our institution. We conducted cognitive building exercises for generating appropriate questions. This involved meeting with individual staff physicians and asking them to suggest risk factors that they felt were important in predicting failure with oral antibiotic therapy for SSTIs. This process was repeated until question saturation was reached. Selected emergency medicine and infectious disease specialists then participated in a pilot survey to assess for content and face validity. The survey was created using SurveyMonkey software (SurveyMonkey Inc., Palo Alto, CA). The initial part of the survey was related to physician approach to the management of SSTIs. The latter portion focused on physician opinion of risk factors important in predicting failure with oral antibiotics for SSTIs, and this was assessed using a 7-point Likert scale.

A pre-notification email was sent out prior to the survey using the modified Dillman method. Non-responders were sent three and two reminders at 2-week intervals to CAEP and AMMI members, respectively.

\section{Data analysis}

Data were analysed using descriptive statistics. In addition, comparisons between the CAEP and AMMI responses were evaluated by unpaired two-tailed t-tests (see the supplementary appendix). The study was approved by the research ethics board at our institution.

\section{RESULTS}

Overall, 391 of 1060 emergency physicians responded to the survey (a response rate of 37\%). By region, the majority of respondents were from Western and Central Canada. Physician demographics are presented in Table 1.

Physicians were asked what factors they considered for patients with SSTIs to help determine the need for administering at least one dose of intravenous antibiotics (Table 2). Emergency physician respondents relied heavily on both clinical impression (97.4\%) and patient comorbidities (87.7\%). Only a minority of physicians reports using guidelines or classification tools in their decision-making.

Results for physician approach to management of SSTIs are presented in Table 3. Cephalexin and cefazolin are the preferred oral and intravenous antibiotics 


\begin{tabular}{ll}
\hline Table 1. Demographics of the survey respondents \\
\hline $\begin{array}{l}\text { CAEP } \\
n=391 / 1060 \\
(36.9 \%)\end{array}$ \\
Characteristic \\
\hline Practice setting (\%) \\
Teaching hospital \\
Community hospital \\
Median years in practice \\
Median number of hours providing \\
patient care per week & 41.9 \\
Regions of Canada (\%) & 15 \\
$\quad$ Western Canada & 30 \\
Central Canada & \\
Atlantic Canada & 34 \\
Northern Canada & 54 \\
\hline CAEP = Canadian Association of Emergency Physicians. & 12 \\
\hline
\end{tabular}

\begin{tabular}{l}
$\begin{array}{l}\text { Table 2. Factors physicians consider to determine whether to } \\
\text { give IV antibiotics for skin and soft tissue infections (SSTIs) }\end{array}$ \\
$\begin{array}{l}\text { CAEP } \\
(n=391)\end{array}$ \\
\hline How do you determine whether to give IV \\
antibiotics for SSTIs? (Select as many as are \\
appropriate.) (\%) \\
Clinical impression \\
Patient comorbidities \\
Blood tests \\
IDSA guidelines/classification tools \\
Other \\
\hline CAEP= Canadian Association of Emergency Physicians; IDSA= Infectious Disease \\
Society of America.
\end{tabular}

to manage SSTIs, respectively. A significant proportion of emergency physician respondents suggested ceftriaxone as a first choice for parenteral therapy (18.9\%). Most respondents selected 7 days of therapy with oral antibiotics. The majority of respondents suggested that 48 hours was an appropriate time to consider treatment failure with oral antibiotics (55.8\%). Although most respondents indicated that they would switch to parenteral therapy in the event of treatment failure with oral antibiotics, $13 \%$ of respondents indicated that they would select another oral antibiotic rather than switch to parenteral therapy. There was a lack of clear consensus for the appropriate time to reassess patients following the first dose of intravenous antibiotics; $44 \%$ of emergency physician respondents favored reassessment at 24 hours. Finally, emergency physician

\begin{tabular}{|c|c|}
\hline Questions (\%) & $\begin{array}{c}\text { CAEP } \\
(n=391)\end{array}$ \\
\hline \multicolumn{2}{|c|}{ First choice of oral antibiotics for SSTIs ( $p=0.34$ ) } \\
\hline Cephalexin & 89.0 \\
\hline Amoxicillin-Clavulanate & 3.6 \\
\hline Other & 7.4 \\
\hline \multicolumn{2}{|c|}{ First choice of IV antibiotics for SSTIs $(p<0.0001)$} \\
\hline Cefazolin & 76.5 \\
\hline Ceftriaxone & 18.9 \\
\hline Other & 4.6 \\
\hline \multicolumn{2}{|c|}{$\begin{array}{l}\text { Average duration of therapy with oral antibiotics for } \\
\text { SSTIs }(p<0.0001)\end{array}$} \\
\hline 3 days & 0.3 \\
\hline 5 days & 5.6 \\
\hline 7 days & 65.7 \\
\hline 10 days & 26.8 \\
\hline Other & 1.6 \\
\hline \multicolumn{2}{|c|}{$\begin{array}{l}\text { How long does a patient have to be on oral } \\
\text { antibiotics before you consider treatment failure? } \\
(p<0.0001)\end{array}$} \\
\hline $24 \mathrm{~h}$ & 7.7 \\
\hline $36 \mathrm{~h}$ & 6.1 \\
\hline $48 \mathrm{~h}$ & 55.8 \\
\hline $72 \mathrm{~h}$ & 26.8 \\
\hline $96 \mathrm{~h}$ & 2.3 \\
\hline Other & 1.3 \\
\hline \multicolumn{2}{|c|}{$\begin{array}{l}\text { If you determine that a patient has suffered a } \\
\text { treatment failure, which of the following are you } \\
\text { most likely to do next? }(p=0.03)\end{array}$} \\
\hline Switch to another oral antibiotic. & 13.0 \\
\hline Switch to an IV antibiotic. & 85.7 \\
\hline Unsure & 1.3 \\
\hline \multicolumn{2}{|c|}{$\begin{array}{l}\text { Recommended clinical reassessment following } \\
\text { first dose of IV antibiotics? }(p=0.04)\end{array}$} \\
\hline$<24 \mathrm{~h}$ & 6.7 \\
\hline $24 \mathrm{~h}$ & 44.3 \\
\hline $48 \mathrm{~h}$ & 24.3 \\
\hline$\geq 72 \mathrm{~h}$ & 22.5 \\
\hline Other & 2.3 \\
\hline \multicolumn{2}{|l|}{ Setting for subsequent IV doses } \\
\hline Return to ED & 40.9 \\
\hline Home or community & 36.6 \\
\hline ID clinic & 16.4 \\
\hline Other & 6.1 \\
\hline
\end{tabular}

respondents were asked to identify the most common setting for subsequent intravenous antibiotic doses. Although the majority indicated a return to the ED $(40.9 \%)$, there were significant responses indicating 
home or community administration $(36.6 \%)$ or an infectious disease clinic (16.4\%).

Of emergency physician respondents, $94.4 \%$ indicated that they would consider employing a clinical decision rule to predict failure with oral antibiotics for SSTIs. The majority of respondents who indicated that they would use a clinical decision rule felt that a $10 \%$ or $5 \%$ miss rate would be acceptable (Figure 1).

Individual risk factors were defined as high risk for treatment failure if the median score was 6 or 7

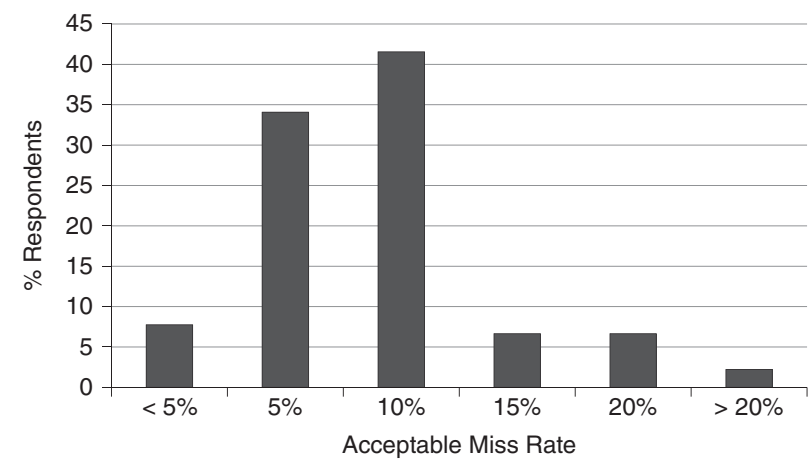

Figure 1. Acceptable Miss Rate for a Proposed Clinical Decision Rule According to CAEP Physician Respondents

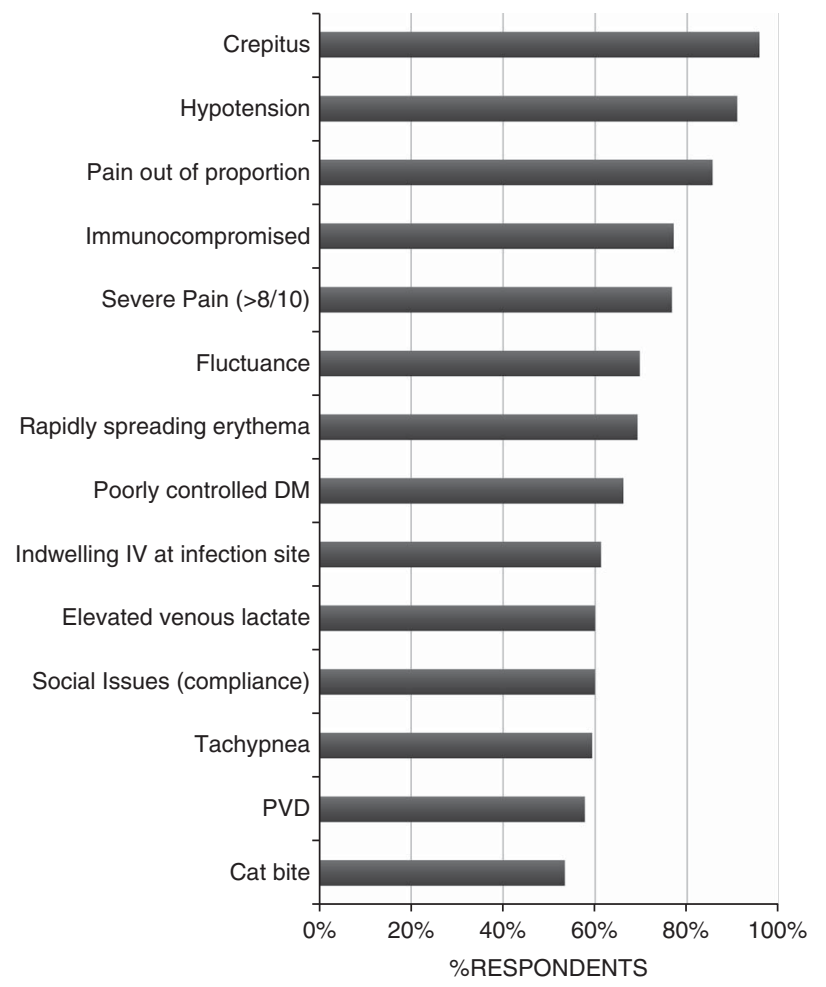

Figure 2. CAEP Respondents Endorsing Risk Factors for Oral Antibiotic Treatment Failure (Median Score $\geq 6 / 7$ ) CAEP $=$ Canadian Association of Emergency Physicians (out of 7). Of 42 potential risk factors, emergency physicians endorsed 14 risk factors as high risk for predicting treatment failure (Figure 2). Six risk factors (immune compromise, poorly controlled diabetes mellitus, indwelling peripheral intravenous line at the infection site, elevated venous lactate, tachypnea, and cat bite) were not considered to be high risk by the infectious disease specialists (AMMI) group.

\section{DISCUSSION}

Following the participation of 391 emergency physicians and 72 infectious disease specialists, our survey showed a clear lack of consensus for the approach to management of SSTIs. Although the majority of emergency physician respondents rely on clinical impression and comorbidities to guide the decision to treat with parenteral therapy, there is significant variability concerning important management decisions for SSTIs amongst emergency physician respondents. Examples include optimal time to clinical reassessment following oral and intravenous therapy, duration of therapy with oral antibiotics, and the time point at which treatment failure with oral therapy should be considered. Furthermore, the respondents have endorsed many risk factors felt to predict failure with oral antibiotics for SSTIs. Of these risk factors, items such as the patient reporting severe pain, poor compliance due to social issues, and tachypnea are likely not considered by a majority of physicians when considering potential treatment failure with oral antibiotics. A recent study by Peterson et al. identified five risk factors that were independently associated with treatment failure, although the authors did not discriminate between oral and parenteral therapies. ${ }^{22}$ An overwhelming majority of emergency physicians indicated that they would use a clinical decision rule to predict failure with oral antibiotics, and most respondents would accept a $10 \%$ or $5 \%$ miss rate. Although attempts to derive a clinical decision rule to predict the need for admission for patients with SSTIs have been unsuccessful to date, ${ }^{23}$ no studies have attempted to derive a decision rule to predict failure with oral antibiotic therapy. This study has demonstrated that there is a lack of consensus regarding the approach to managing non-purulent SSTIs and has identified several risk factors felt to predict treatment failure, which merit further investigation to improve physician approach to this common clinical presentation. 
To our knowledge, this survey is the first to assess how Canadian emergency physicians manage patients with SSTIs, and the first to gauge emergency physician opinion on which risk factors are felt to predict treatment failure with oral antibiotics. Furthermore, emergency clinicians identified several perceived "high risk" factors for treatment failure with oral antibiotic therapy. This study has ultimately shown that there lacks agreement on how to best manage this common clinical problem, and that perhaps we should consider specific risk factors when determining the appropriate route of antibiotic therapy.

This study has several potential limitations. One limitation is that members of CAEP may not be fully representative of emergency physicians, reflecting a sampling bias. However, this group is the only national Canadian organization of emergency physicians that is also involved in the development of practice guidelines. There is also the chance that the responses of nonresponders may have differed significantly from those who did participate in the survey (non-response bias). Physician approach to management of non-purulent SSTIs may be affected by variations in local resistance patterns and rates of MRSA. Finally, the comparison of physician groups (see the supplementary appendix) may be open to criticism, as one might argue that each group sees a different disease spectrum concerning SSTIs.

Our findings reveal important clinical implications, having demonstrated a scarcity of existing evidence combined with a lack of consensus on the optimal approach to managing SSTIs. Furthermore, respondents have highlighted several risk factors felt to predict treatment failure with oral therapy. We feel that many of these identified risk factors may not be considered by a majority of emergency physicians when deciding on oral versus parenteral therapy. Ultimately, our findings strengthen the argument for further investigations regarding the management of SSTIs.

The survey demonstrates significant variability regarding physician management of SSTIs, and we have identified several perceived risk factors for treatment failure with oral antibiotics that should be assessed in future studies.

Acknowledgements: The authors would like to thank Angela Marcantonio, My-Linh Tran, and Risa Shorr for their assistance in this study.

Competing interests: None declared.

\section{SUPPLEMENTARY MATERIALS}

For supplementary material/s referred to in this article, please visit http://dx.doi.org/doi:10.1017/cem.2016.347

\section{REFERENCES}

1. Phoenix G, Das S, Joshi M. Diagnosis and management of cellulitis. BMF 2012;345:e4955.

2. Dong SL, Kelly KD, Oland RC, et al. ED management of cellulitis: a review of five urban centers. Am 7 Emerg Med 2001;19(7):535-40.

3. Powers RD. Soft tissue infections in the emergency department: the case for the use of "simple" antibiotics. South Med 7 1991;84(11):1313-5.

4. Haran JP, Hayward G, Skinner S, et al. Factors influencing the development of antibiotic associated diarrhea in ED patients discharged home: risk of administering IV antibiotics. Am 7 Emerg Med 2014;32(10):1195-9, doi:10.1016/j. ajem.2014.07.015.

5. May L, Harter K, Yadav K, et al. Practice patterns and management strategies for purulent skin and soft-tissue infections in an urban academic ED. Am 7 Emerg Med 2012;30(2):302-10.

6. Murray H, Stiell I, Wells G. Treatment failure in emergency department patients with cellulitis. CFEM 2005; 7(4):228-34.

7. Wallin TR, Hern HG, Frazee BW. Community-associated methicillin-resistant Staphylococcus aureus. Emerg Med Clin North Am 2008;26(2):431-55, ix.

8. Vayalumkal JV, Suh KN, Toye B, et al. Skin and soft tissue infections caused by methicillin-resistant Staphylococcus aureus (MRSA): an affliction of the underclass. CFEM 2012;14(6):335-43.

9. Moran GJ, Krishnadasan A, Gorwitz RJ, et al. Methicillinresistant $\mathrm{S}$. aureus infections among patients in the emergency department. N Engl 7 Med 2006;355(7):666-74.

10. Stevens DL, Bisno AL, Chambers HF, et al. Practice guidelines for the diagnosis and management of skin and soft tissue infections: 2014 update by the Infectious Diseases Society of America. Clin Infect Dis 2014;59(2): e10-52.

11. Eron LJ, Lipsky BA, Low DE, et al. Managing skin and soft tissue infections: expert panel recommendations on key decision points. 7 Antimicrob Chemother 2003;52(Suppl 1): i3-17.

12. CREST Guidelines. Guidelines on the management of cellulitis in adults; 2005. Available at: http://www.crestni.org.uk.

13. Marwick C, Broomhall J, McCowan C, et al. Severity assessment of skin and soft tissue infections: cohort study of management and outcomes for hospitalized patients. 7 Antimicrob Chemother 2011;66(2):387-97.

14. Perello-Alzamora MR, Santos-Duran JC, Sanchez-Barba M, et al. Clinical and epidemiological characteristics of adult patients hospitalized for erysipelas and cellulitis. Eur 7 Clin Microbiol Infect Dis 2012;31(9):2147-52.

15. Volz KA, Canham L, Kaplan E, et al. Identifying patients with cellulitis who are likely to require inpatient admission 
after a stay in an ED observation unit. Am 7 Emerg Med 2013;31(2):360-4.

16. Talan DA, Salhi BA, Moran GJ, et al. Factors associated with decision to hospitalize emergency department patients with skin and soft tissue infection. West 7 Emerg Med 2015;16(1):89-97.

17. Kilburn SA, Featherstone P, Higgins B, et al. Interventions for cellulitis and erysipelas. Cochrane Database Syst Rev 2010;6:CD004299.

18. Calder LA, Arnason T, Vaillancourt C, et al. How do emergency physicians make discharge decisions? Emerg Med f 2015;32(1):9-14, doi:10.1136/emermed-2013-202421.

19. Rogenstein C, Kelly AM, Mason S, et al. An international view of how recent-onset atrial fibrillation is treated in the emergency department. Acad Emerg Med 2012;19(11): 1255-60, doi:10.1111/acem.12016.
20. Jensen JL, Vaillancourt C, Tweedle J, et al. Factors associated with the successful recognition of abnormal breathing and cardiac arrest by ambulance communications officers: a qualitative iterative survey. Prehosp Emerg Care 2012;16(4): 443-50.

21. Perry JJ, Goindi R, Symington C, et al. Survey of emergency physicians' requirements for a clinical decision rule for acute respiratory illnesses in three countries. C7EM 2012;14(2):83-9.

22. Peterson D, McLeod S, Woolfrey K, et al. Predictors of failure of empiric outpatient antibiotic therapy in emergency department patients with uncomplicated cellulitis. Acad Emerg Med 2014;21(5):526-31.

23. Sabbaj A, Jensen B, Browning MA, et al. Soft tissue infections and emergency department disposition: predicting the need for inpatient admission. Acad Emerg Med 2009; 16(12):1290-7, doi:10.1111/j.1553-2712.2009.00536.x. 